\title{
Artificial Phosphorylation Removes Gelsolin's Dependence on Calcium
}

\author{
Kingo Takiguchi*, Shigeko Yamashiro-Matsumura, and Fumio Matsumura \\ Department of Molecular Biology and Biochemistry, Busch Campus, Rutgers University Piscataway, New \\ Jersey 08855-1059, USA
}

\begin{abstract}
Gelsolin is one of the best known actin-binding proteins with several distinct activities regulated by calcium. Using a kinase fraction isolated from mitotic HeLa cells, we found that the plasma form of gelsolin can be phosphorylated at a site located within the $\mathrm{NH}_{2}$-terminus region which does not exist in the cytoplasmic form. After this phosphorylation, gelsolin no longer requires $\mathrm{Ca}^{2+}$ for activity; it severs and subsequently caps actin filaments, and nucleates filament formation in $\mathrm{Ca}^{2+}$-free solution. These findings may clarify the mechanism of gelsolin regulation by $\mathrm{Ca}^{2+}$, and indicate that changes in electrical interactions between the $\mathrm{NH}_{2-}$ and $\mathrm{COOH}^{-}$ terminal ends are important for this regulation. Moreover, since only a single site is phosphorylated, and since the phosphorylated region does not contribute to this protein's own activity, the results suggest that a single chemical charge modification at a site away from the protein's core structure, such as this phosphorylation site, is sufficient to alter the protein's function.
\end{abstract}

Key words: gelsolin/actin-severing activity/calcium regulation/phosphorylation/flow birefringence/protein engineering

Gelsolin is a $90 \mathrm{kDa} \mathrm{Ca}{ }^{2+}$-regulated actin-binding protein found in the cytoplasm of eukaryotes as well as in blood plasma (Kwiatkowski et al., 1988; Yin and Stossel, 1979; Yin et al., 1984; Yin, 1987). Both the plasma and the cytoplasmic forms of gelsolin can be isolated from the same source, are encoded by a single gene and differ as the result of alternative splicing (Kwiatkowski et al., 1986; Stella et $a l ., 1994)$. The cytoplasmic form of gelsolin has been implicated in the regulation of the actin cytoskeleton. It is thought to control the length and number of actin filaments (F-actin) (Lin et al., 1997), and it is required for the rapid locomotion of moving cells (Cunningham et al., 1991; Witke et al., 1995). On the other hand, gelsolin secreted in the plasma plays a key role in scavenging F-actin from the circulation. It rapidly severs plasma F-actin released from dead cells and prevents the elevation of blood viscosity (Haddad et al., 1990; Vasconcellos and Lind, 1993).

Only when micromolar concentrations of $\mathrm{Ca}^{2+}$ are present in solution can gelsolin sever F-actin and subsequently form

\footnotetext{
* To whom correspondence should be addressed:

* Present address: Division of Molecular Biology, Graduate School of Science, Nagoya University, Furo-cho, Chikusa-ku, Nagoya 4648602, Japan.

Tel: +81-52-789-2556, Fax: +81-52-789-3001

E-mail: j46037a@nucc.cc.nagoya-u.ac.jp

Abbreviations: PMSF, phenymethanesulfonyl fluoride; DTT, dithiothreitol; CBB, Coomassie brilliant blue.
}

a cap on its newly exposed barbed end, which blocks the monomer association at that end. Because the two ends of F-actin have significantly different rates of assembly and disassembly, not only is the length of F-actin shortened, but the total amount of assembled actin is decreased, when gelsolin is active. This results in an increase in the critical concentration necessary for actin polymerization. In addition to these two activities, gelsolin has a third activity: stimulation of actin nucleation. Formation of the nucleation site, which consists of an actin trimer, is necessary for actin assembly before its elongation. Because the assembly of a nucleation site is relatively slower than actin elongation, a lag phase is seen in the early stages of polymerization. When $\mathrm{Ca}^{2+}$ is present, gelsolin can shorten this lag phase by its actin-nucleation activity, while the amount of F-actin at equilibrium is decreased by the other activities of gelsolin.

Gelsolin has six structurally related segments. An analysis of the properties of the proteolytically derived fragments of gelsolin (Bryan and Hwo, 1986; Chaponnier et al., 1986; Kwiatkowski et al., 1985) suggests that $\mathrm{Ca}^{2+}$ binds to the $\mathrm{COOH}$-terminal half of gelsolin and induces a conformational change (Bryan and Hwo, 1986; Kilhoffer and Gerard, 1985; Kwiatkowski et al., 1986; Lamb et al., 1993) which disrupts connections (binding or interaction) between the $\mathrm{NH}_{2}$-terminal and $\mathrm{COOH}$-terminal halves of the protein, permitting the $\mathrm{NH}_{2}$-terminal half to sever F-actin (Burtnick et al., 1997; Lin et al., 1997). Severing by this $\mathrm{NH}_{2}$-terminal 
region is $\mathrm{Ca}^{2+}$ independent, and requires the participation of two actin binding domains located within the $\mathrm{NH}_{2}$-terminal segment (S1) and segment 2 and 3 (S2-3). The S1 region binds to actin monomers and to the ends of filaments with high affinity, while S2-3 binds to the side of F-actin (Bryan, 1988; Yin, 1987).

We report here that plasma gelsolin isolated from the serum, but not from the cytoplasm, is phosphorylated with kinase activity isolated from mitotic HeLa cells. Phosphorylated gelsolin becomes active in the absence of calcium, but shows the same CD spectra as the unphosphorylated form. An analysis of proteolytically derived fragments of phosphorylated plasma gelsolin suggests that this phosphorylation occurs within an additional leader sequence at its $\mathrm{NH}_{2}$ terminus which exists only in the plasma form of gelsolin. These results suggest that this artificial phosphorylation at the $\mathrm{NH}_{2}$-terminus liberates gelsolin from its calcium dependence.

\section{Materials and Methods}

\section{Protein}

Actin was purified from rabbit skeletal muscle as previously described (Takiguchi, 1991). Plasma and cytoplasmic gelsolin were purified from calf or porcine serum and porcine heart, respectively (Ishikawa et al., 1989; Rouayrenc et al., 1984). Gelsolin was phosphorylated as described previously (Yamashiro et al., 1990). Briefly, gelsolin $(0.8 \mathrm{mg} / \mathrm{ml})$ was incubated at $22^{\circ} \mathrm{C}$ for $2 \mathrm{hr}$ in Buffer A (15 mM imidazole $\mathrm{pH} 7.0,5 \mathrm{mM} \mathrm{MgCl}_{2}, 0.2 \mathrm{mM}$ EGTA, $75 \mathrm{mM}$ $\mathrm{KCl}, 500 \mathrm{nM}$ protein kinase A inhibitor peptide and $2 \mathrm{mM}$ ATP) with the kinase fraction isolated from mitotic HeLa cells. The samples were then dialyzed against $25 \mathrm{mM}$ Tris- $\mathrm{HCl} \mathrm{pH}$ 7.6, $0.5 \mathrm{mM}$ $\mathrm{CaCl}_{2}$ and $0.2 \mathrm{mM}$ PMSF at $4^{\circ} \mathrm{C}$ overnight and then used. The amount of phosphorylation was determined using $\left[\gamma^{32} \mathrm{P}\right]$ ATP.

Occasionally, to further purify phosphorylated calf serum gelsolin, the sample was applied to a DEAE-cellulose column equilibrated with the dialysis buffer noted above. Phosphorylated calf serum gelsolin was eluted with the same dialysis buffer containing $50 \mathrm{mM} \mathrm{NaCl}$, and then dialysed against $20 \mathrm{mM}$ imidazole $\mathrm{pH}$ 7.0, $100 \mathrm{mM} \mathrm{KCl}$, and $0.2 \mathrm{mM}$ PMSF. This purified fraction is termed DEAE-purified phosphorylated gelsolin. Using this procedure, a gelsolin sample in which $80-90 \%$ of the protein was phosphorylated could be obtained. For control experiments, an unphosphorylated gelsolin sample was applied to the DEAE-cellulose column and then used in the same way. This sample was termed DEAEpurified unphosphorylated gelsolin. The actin-binding activity of gelsolin was assayed as described previously (Yamashiro-Matsumura and Matsumura, 1985).

Gelsolin was also phosphorylated with cdc2 beads using the same conditions as noted above using the kinase fraction isolated from mitotic HeLa cells. Briefly, gelsolin was incubated with cdc2 beads for $1 \mathrm{~h}$ at room temperature. Those cdc2 beads were prepared as described previously (Yamashiro et al., 1990), and essentially were protein A beads bound to p34 cdc2 kinase antibodies.
The beads were subsequently incubated with the kinase fraction from mitotic HeLa cells, and after washing with phosphate-buffered saline, they were used as cdc2 beads. It is noted here that essentially the same results were obtained using either the kinase fraction or the cdc2 beads for gelsolin phosphorylation.

Proteolytic analysis of phosphorylated plasma gelsolin using $\alpha$ chymotrypsin was performed according to Bryan and Hwo (1986).

\section{Assays for gelsolin activities}

Gelsolin activities were monitored by flow birefringence (Arisaka et al., 1975; Ishikawa et al., 1989). For severing activity, $12 \mu \mathrm{M} \mathrm{F-}$ actin and various concentrations of phosphorylated or unphosphorylated gelsolin were incubated in $20 \mathrm{mM}$ imidazole $\mathrm{pH} 7.0,100$ $\mathrm{mM} \mathrm{KCl}, 2 \mathrm{mM} \mathrm{MgCl} 2,0.2 \mathrm{mM}$ DTT, $0.25 \mathrm{mM}$ ATP and $0.2 \mathrm{mM}$ $\mathrm{CaCl}_{2}$ or $2 \mathrm{mM} \mathrm{EGTA}$ at $22^{\circ} \mathrm{C}$ for $30 \mathrm{~min}$, and then each sample was assayed.

To follow the severing activity of plasma gelsolin during its phosphorylation, $0.25 \mathrm{mg} / \mathrm{ml}$ unphosphorylated gelsolin was incubated at $22^{\circ} \mathrm{C}$ in Buffer A with the kinase fraction. Aliquots $(15 \mu \mathrm{l})$ of the mixture were withdrawn at various times and mixed with $135 \mu \mathrm{l}$ of an F-actin-containing solution (final concentration of 20 $\mathrm{mM}$ imidazole $\mathrm{pH} 7.0,100 \mathrm{mM} \mathrm{KCl}, 2 \mathrm{mM} \mathrm{MgCl} 2,0.2 \mathrm{mM}$ DTT, $0.25 \mathrm{mM}$ ATP, $2 \mathrm{mM}$ EGTA and $12 \mu \mathrm{M}$ F-actin). After incubation at $22^{\circ} \mathrm{C}$ for $40 \mathrm{~min}$, the flow birefringence of the sample was measured. Conversely, to follow the severing activity of phosphorylated plasma gelsolin during its dephosphorylation, $0.2 \mathrm{mg} / \mathrm{ml}$ phosphorylated gelsolin was incubated at $22^{\circ} \mathrm{C}$ in $0.1 \mathrm{M} 2-(\mathrm{N}-$ morpholino) ethanesulfonic acid (MES) pH 6.0 and $0.1 \mathrm{mM} \mathrm{PMSF}$ with $50 \mu \mathrm{g} / \mathrm{ml}$ potato acidic phosphatase. Aliquots $(25 \mu \mathrm{l})$ of the mixture were withdrawn at various times and mixed with $125 \mu \mathrm{l}$ of the F-actin-containing solution (final concentration of $70 \mathrm{mM}$ imidazole $\mathrm{pH}$ 7.0, $60 \mathrm{mM} \mathrm{KCl}, 2 \mathrm{mM} \mathrm{MgCl} 2,0.2 \mathrm{mM}$ DTT, $0.2 \mathrm{mM}$ ATP, $2 \mathrm{mM}$ EGTA or $0.2 \mathrm{mM} \mathrm{CaCl}_{2}$ and $12 \mu \mathrm{M}$ F-actin). After incubation at $22^{\circ} \mathrm{C}$ for $5 \mathrm{~min}$, the flow birefringence of each sample was measured.

For evaluating the capping activity, various concentrations of actin and 0.3 $\mu \mathrm{M}$ DEAE-purified phosphorylated or unphosphorylated gelsolin were incubated in $20 \mathrm{mM}$ imidazole $\mathrm{pH} 7.0,80 \mathrm{mM}$ $\mathrm{KCl}, 5 \mathrm{mM} \mathrm{MgCl} 2,0.2 \mathrm{mM}$ DTT, $1.2 \mathrm{mM}$ ATP and $0.2 \mathrm{mM} \mathrm{CaCl}_{2}$ or $2 \mathrm{mM}$ EGTA at $4{ }^{\circ} \mathrm{C}$ overnight and then at $20^{\circ} \mathrm{C}$ for $3 \mathrm{hr}$. The flow birefringence of each sample was then assayed and the critical concentration of actin polymerization was calculated. Because flow birefringence was difficult to measure at lower actin concentrations when only about $25 \%$ of the gelsolin in the sample tested was phosphorylated, we used DEAE-purified phosphorylated gelsolin to evaluate capping activity, with or without calcium. Most of the gelsolin molecules in that sample were phosphorylated, as described above.

For nucleation activity, $12 \mu \mathrm{M}$ G-actin and $0.15 \mu \mathrm{M}$ phosphorylated or unphosphorylated gelsolin were incubated in $7.5 \mathrm{mM}$ Tris$\mathrm{HCl} \mathrm{pH}$ 8.0, $2 \mathrm{mM} \mathrm{MgCl}_{2}, 0.3 \mathrm{mM}$ DTT, $1 \mathrm{mM}$ ATP and $0.2 \mathrm{mM}$ $\mathrm{CaCl}_{2}$ or $2 \mathrm{mM} \mathrm{EGTA}$ at $22^{\circ} \mathrm{C}$ for $15 \mathrm{~min}$. Actin polymerization was initiated by the addition of $2 \mathrm{mM} \mathrm{MgCl}_{2}$ and $0.15 \mathrm{M} \mathrm{KCl}$ (final concentrations), and the increase of flow birefringence was 
followed.

\section{Results}

\section{Phosphorylation of plasma gelsolin}

The kinase activity isolated from mitotic HeLa cells and cdc2 beads can phosphorylate plasma gelsolin isolated from porcine or calf serum (Fig. 1A), but can not phosphorylate cytoplasmic gelsolin isolated from porcine heart (Fig. 1E). Since gelsolin exists in two forms (plasma and cytoplasmic), that are encoded by a single gene and that differ as the result of alternative splicing, both forms contain the same core structure and differ only at the $\mathrm{NH}_{2}$-terminus (Bryan and Hwo, 1986; Kwiatkowski et al., 1985, 1986; Stella et al., 1994). Only plasma gelsolin has an extended leader sequence at its $\mathrm{NH}_{2}$-terminus, and therefore, the potential phosphorylation site was expected to reside in that sequence. To confirm the phosphorylation site, calf and por- cine plasma gelsolins phosphorylated in the presence of $[\gamma-$ $\left.{ }^{32} \mathrm{P}\right]$ ATP were treated with $\alpha$-chymotrypsin (Bryan and Hwo, 1986), and the fragments were then analyzed by western blotting using a gelsolin antibody that recognizes the $\mathrm{COOH}$-terminus, followed by autoradiography (Fig. 1, B and $\mathrm{C}$ ). Since the amino acid sequence of the core structure of gelsolin is highly conserved, this $90 \mathrm{kDa}$ protein generally produces five well-known major fragments after $\alpha$-chymotryptic digestion (Fig. 1D) (Bryan and Hwo, 1986; Bryan 1988; Chaponnier et al., 1986; Kwiatkowski et al., 1985; Rouayrenc et al., 1986; Way and Weeds, 1988). Gelsolin was initially cleaved into a $40 \mathrm{kDa} \mathrm{NH}$-half and a $45 \mathrm{kDa}$ $\mathrm{COOH}$-terminal half. The $40 \mathrm{kDa} \mathrm{NH}$-half was further proteolyzed into a $17 \mathrm{kDa}$ fragment (called CT17N) and a 30 $\mathrm{kDa}$ fragment, while the $45 \mathrm{kDa} \mathrm{COOH}$-terminal half was subsequently processed into a $40 \mathrm{kDa}$ fragment. The CT17N fragment, the $30 \mathrm{kDa} \mathrm{NH}_{2}$-half fragment, and the $\mathrm{COOH}$-terminal half roughly correspond to the $\mathrm{S}-1, \mathrm{~S} 2-3$, and S4-6 segments of gelsolin, respectively (Yin, 1987). It
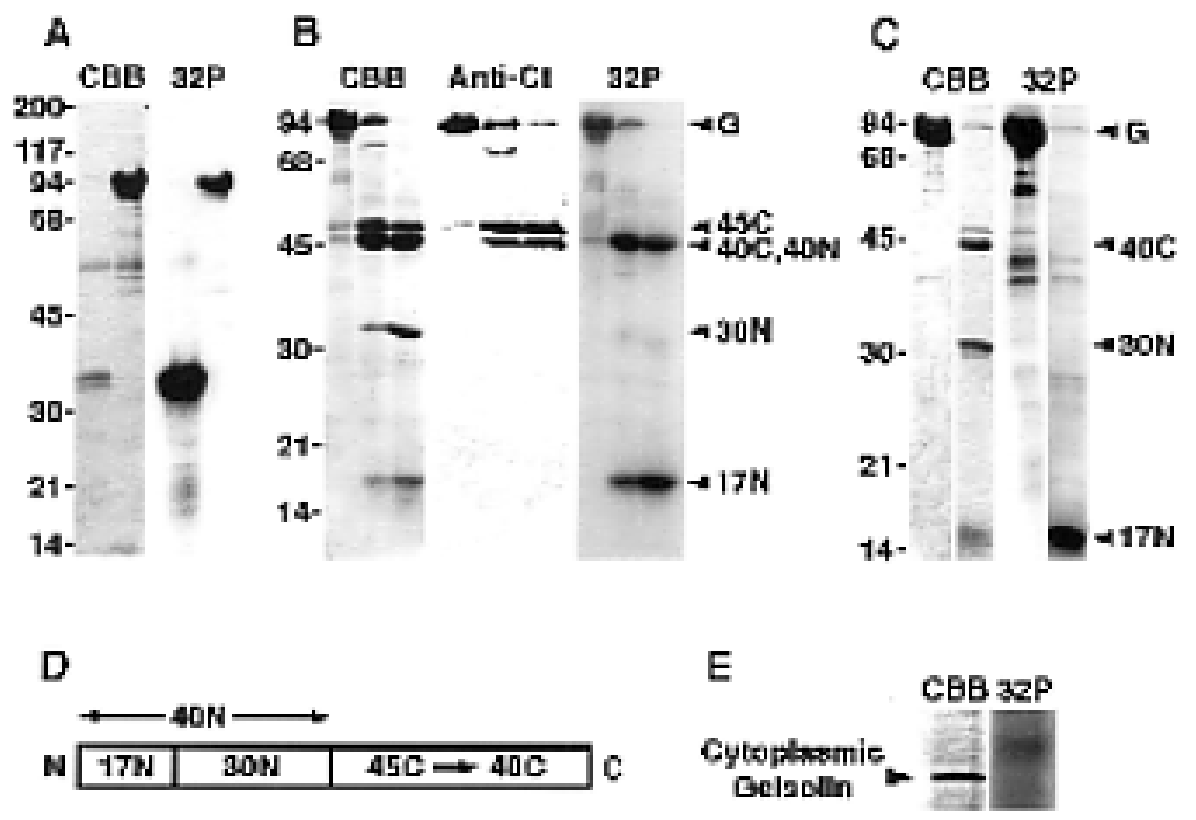

Fig. 1. Plasma gelsolin is phosphorylated by a kinase fraction isolated from mitotic HeLa cells. (A) Calf serum gelsolin phosphorylated by cdc2 beads. The left side panel shows CBB staining of SDS-PAGE of histone H1 (left lane) and calf serum gelsolin (right lane). The right panel shows an autoradiograph of the same gel (32P). Histone $\mathrm{H} 1(180 \mu \mathrm{g} / \mathrm{ml})$ and gelsolin $(0.4 \mathrm{mg} / \mathrm{ml})$ were incubated with cdc 2 beads and $\left[\gamma^{-32} \mathrm{P}\right]$ ATP for $1 \mathrm{~h}$ at room temperature. Protein A beads binding a p34 cdc2 kinase antibody were incubated with a kinase fraction from mitotic HeLa cells. After washing with phosphate-buffered saline, the beads were used as cdc2 beads. The conditions are the same as phosphorylation using the kinase fraction. (B) Proteolytic analysis of phosphorylated calf serum gelsolin. The left side panel shows CBB staining of SDS-PAGE of phosphorylated calf serum gelsolin incubated with $\alpha$-chymotrypsin (lanes, left to right, show incubation times of 0,40 , and $120 \mathrm{~min}$, respectively). The center panel shows western blotting of the gel using an antibody which recognizes the COOH-terminal half of gelsolin (Anti-Ct). The right side panel shows an autoradiograph of the same gel (32P). (C) Proteolytic analysis of phosphorylated porcine serum gelsolin. The left panel shows CBB staining of SDS-PAGE of phosphorylated porcine serum gelsolin incubated with $\alpha$-chymotrypsin (left and right lanes show incubation times of 0 and $120 \mathrm{~min}$, respectively). The right panel shows an autoradiograph of the same gel (32P). Left side numbers indicate the positions of each molecular weight (kDa). Identified bands are, G, gelsolin; 45C, CT45C fragment; 40C, CT40C fragment; 40N, CT40N fragment; $30 \mathrm{~N}, 30 \mathrm{kDa} \mathrm{NH}$-half fragment; 17N, CT17N fragment (see Kwiatkowski et al., 1985). (D) A schematic model shows the five major fragments generally produced after $\alpha$-chymotryptic treatment of gelsolin (Bryan and Hwo, 1986; Kwiatkowski et al., 1985; Rouayrenc et al., 1986). (E) Porcine heart gelsolin is not phosphorylated by the same kinase fraction. Left panel shows CBB staining of SDS-PAGE of partially purified porcine heart gelsolin. Right panel shows an autoradiograph of the same gel (32P). Porcine heart gelsolin was incubated with the kinase fraction for $2 \mathrm{~h}$ at room temperature. 
can be seen that only the CT17N fragment was phosphorylated (Fig. 1B). Similar results were obtained when porcine serum gelsolin rather than calf serum gelsolin was phosphorylated (Fig. 1, B and C). Since the kinase fraction isolated from mitotic HeLa cells contains mainly cdc2 kinase activity (Yamashiro et al., 1990, 1991), and since plasma gelsolin was also phosphorylated by cdc2 beads (Fig. 1A), cdc2 kinase is responsible for this gelsolin phosphorylation (Yamakita et al., 1994; Yamashiro et al., 1990, 1991). The consensus phosphorylation sequence of this kinase can be found in gelsolin at several sites (Way and Weeds, 1988; Weeds et al., 1986). Our results, however, show that the phosphorylation site is located near the $\mathrm{NH}_{2}$-terminus of plasma gelsolin, because the CT17N fragment was produced from the $\mathrm{NH}_{2}$-terminal region (Fig. 1D). Phosphorylation at this site was confirmed by an experiment in which cytoplasmic gelsolin isolated from porcine heart was not phosphorylated by this kinase (Fig. 1E). Furthermore, the plasma and cytoplasmic forms contain the same core structure but only the plasma gelsolin form has an extended sequence at its $\mathrm{NH}_{2}$-terminus (Bryan and Hwo, 1986; Kwiatkowski et al., 1985, 1986). Therefore, these results indicate that the phosphorylation site is located within the excessive sequence which only plasma gelsolin has at its $\mathrm{NH}_{2}-$ terminus. It is noted here that, since the maximum efficiency of gelsolin phosphorylation did not exceed one mole/ mole gelsolin (data not shown), only a single site might be phosphorylated.

\section{Actin-severing activity of phosphorylated gelsolin}

Only in the presence of $\mathrm{Ca}^{2+}$ can gelsolin sever F-actin and form a cap on its newly exposed barbed end, or stimulate nucleation for actin polymerization (Yin, 1987). Phosphorylated plasma gelsolin, however, also becomes active in the absence of $\mathrm{Ca}^{2+}$. In the presence of $\mathrm{Ca}^{2+}$, since gelsolin can sever F-actin regardless of whether it is phosphorylated or not, the phosphorylated and the unphosphorylated forms can decrease the amount of F-actin in a similar and concentration dependent manner. On the other hand, in the absence of $\mathrm{Ca}^{2+}$, although the unphosphorylated form completely lost its severing activity, the phosphorylated form could still sever F-actin (Fig. 2A). The severing activity of the phosphorylated sample in the absence of $\mathrm{Ca}^{2+}$ was about $25 \%$ that measured in the presence of $\mathrm{Ca}^{2+}$. This is however, consistent with the fact that about $25 \%$ of the gelsolin in this sample was phosphorylated (data not shown).

This was further confirmed by following the severing activity during gelsolin phosphorylation and dephosphorylation (Fig. 2, B and $\mathrm{C}$, respectively). In the absence of $\mathrm{Ca}^{2+}$ the severing activity increased or decreased with incubation time in the presence of kinase or phosphatase, respectively. The loss of severing activity after phosphatase treatment was due to the decrease in the phosphorylated form of gelsolin molecules as shown by the fact that the activity of

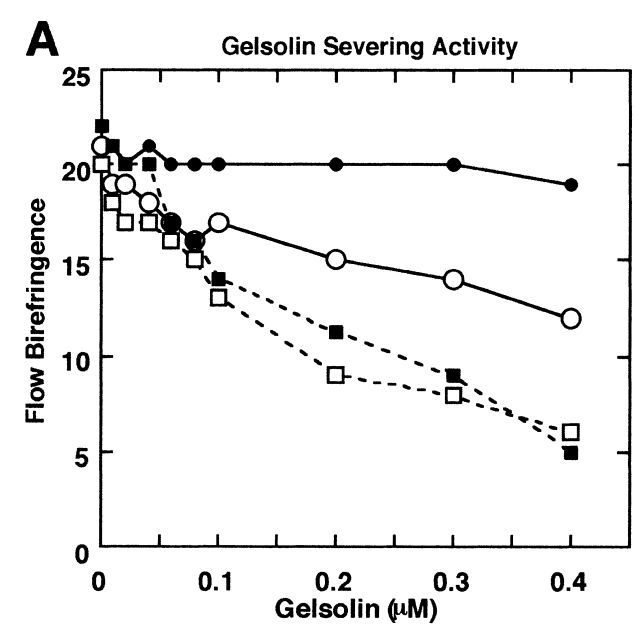

B Activity of Phosphorylated Gelsolin (+ EGTA)

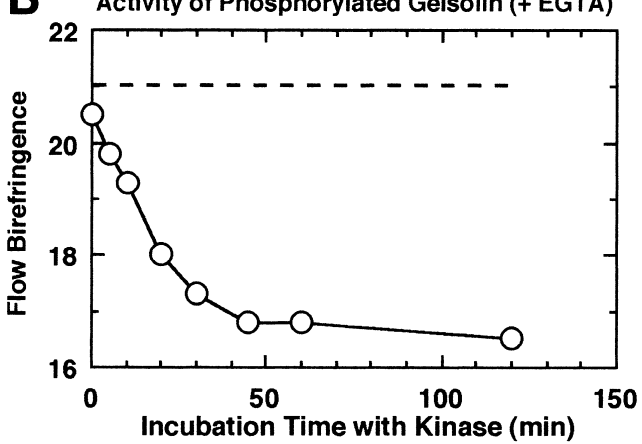

C Activity of Dephosphorylated Gelsolin (+ EGTA)

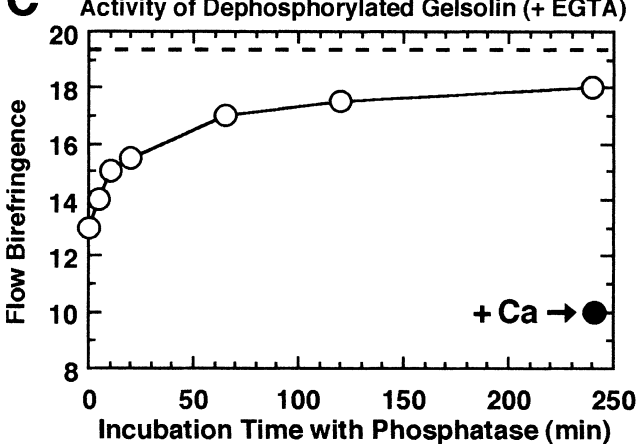

Fig. 2. The actin severing activity of phosphorylated plasma (calf serum) gelsolin. (A) The severing activities at various concentrations of gelsolin. The closed and open circles show the activities of unphosphorylated and phosphorylated gelsolin samples in the presence of 2 mM EGTA, respectively. The closed and open squares show the activities of unphosphorylated and phosphorylated gelsolin samples in the presence of $0.2 \mathrm{mM} \mathrm{CaCl}$, respectively. Note here that similar results were obtained when porcine serum gelsolin was phosphorylated instead of gelsolin from calf serum. (B) The change of the actin severing activity of gelsolin during its phosphorylation by the kinase fraction in the presence of 2 mM EGTA (open circles). (C) The change of the actin severing activity of phosphorylated gelsolin during its dephosphorylation by potato acidic phosphatase in the presence of $2 \mathrm{mM}$ EGTA (open circles). The closed circle indicated by the arrow shows the severing activity of the dephosphorylated plasma gelsolin in the presence of $\mathrm{Ca}^{2+}$. In (B) and (C) the broken line shows flow birefringence under the same conditions when no gelsolin was added. 
the dephosphorylated sample remained in the presence of $\mathrm{Ca}^{2+}$ (Fig. 2C, closed circle). This restoration of the $\mathrm{Ca}^{2+}-\mathrm{de}-$ pendence of gelsolin by phosphatase treatment indicates that the effect of phosphorylation on this protein is reversible.

The actin-severing speed of phosphorylated gelsolin in the presence of $\mathrm{Ca}^{2+}$ was indistinguishable from that of the unphosphorylated protein in the presence of $\mathrm{Ca}^{2+}$, while the activity of the phosphorylated sample in the absence of $\mathrm{Ca}^{2+}$ was $25 \%$ that in the presence of $\mathrm{Ca}^{2+}$ (Fig. 3). This decreased activity of the phosphorylated sample is also consistent with the fact that about $25 \%$ of the gelsolin in this sample was phosphorylated. The results shown in Figure 2A and 3 can be readily explained if the net concentration of gelsolin which can sever F-actin is equal to the phosphorylated gelsolin concentration. These results suggest that the actin-severing mechanism of phosphorylated gelsolin in the absence of calcium, and that of unphosphorylated gelsolin in the presence of calcium are probably the same.

\section{Actin-capping activity of phosphorylated gelsolin}

The two ends of actin filaments have significantly different rates of assembly and disassembly. The barbed ends of Factin polymerize 10 times faster than the pointed ends. Because gelsolin can not only sever actin filaments but also can cap their barbed ends and block the monomer association at those ends, the critical concentration for actin polymerization is increased when gelsolin is active. Therefore,

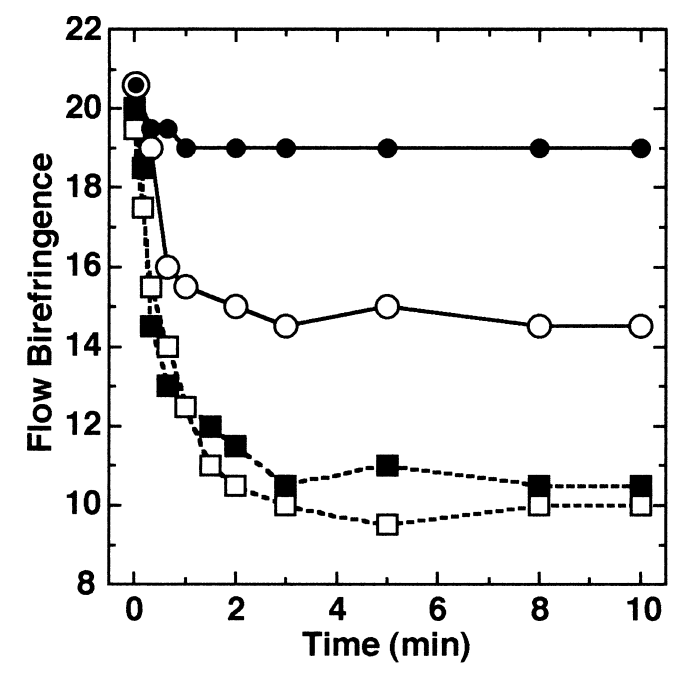

Fig. 3. Time course of actin severing by calf serum gelsolin. The closed and open circles show the time course of the activities of unphosphorylated and phosphorylated gelsolin samples in the presence of $2 \mathrm{mM}$ EGTA, respectively. The closed and open squares show the time course of the activities of unphosphorylated and phosphorylated gelsolin samples in the presence of $1.5 \mathrm{mM} \mathrm{CaCl}_{2}$, respectively. In either case, the concentration of calf serum gelsolin was $0.3 \mu \mathrm{M}$. Note here that similar results were obtained when porcine serum gelsolin was phosphorylated instead of gelsolin from calf serum. under our experimental conditions, both phosphorylated and unphosphorylated gelsolin increased the critical concentration 10-fold in the presence of $\mathrm{Ca}^{2+}$ (Fig. 4A). On the other hand, when $\mathrm{Ca}^{2+}$ was absent, gelsolin which was not phosphorylated lost virtually all its activity (Fig. 4B). The phosphorylated gelsolin, however, still showed its capping activity and increased the actin critical concentration 8 -fold in the absence of $\mathrm{Ca}^{2+}$. It is noted here that the increasing rate of the actin critical concentration when the DEAE-purified
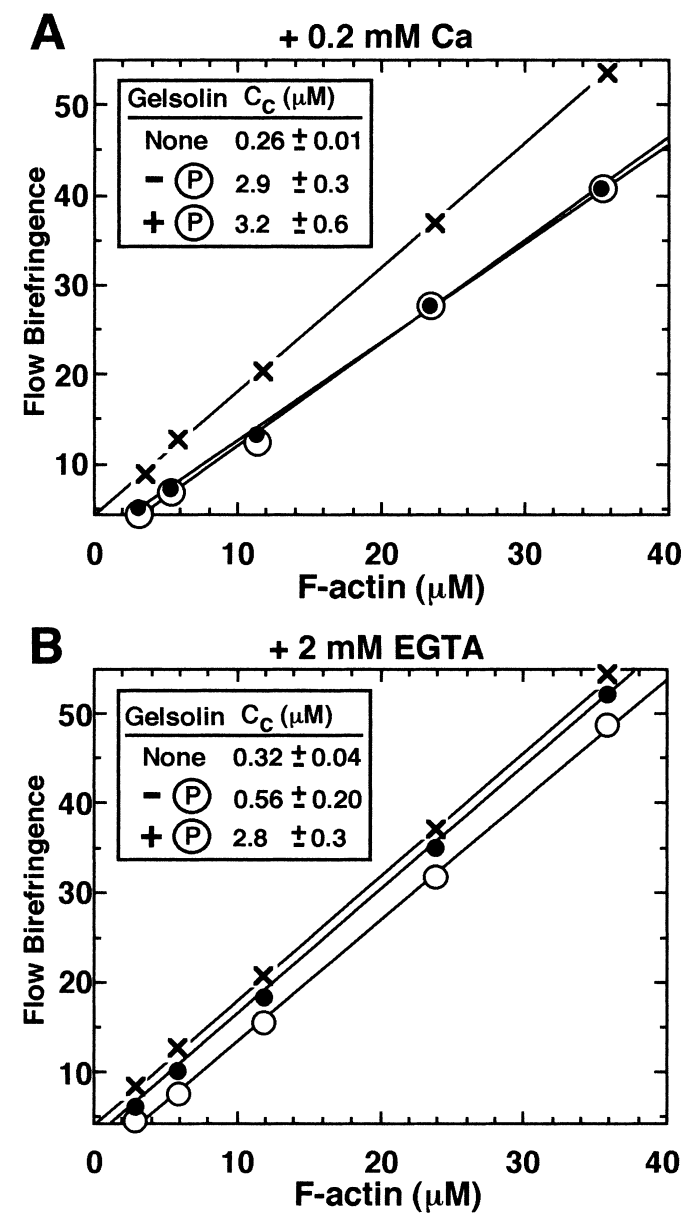

Fig. 4. Actin capping activity of phosphorylated and unphosphorylated plasma (calf serum) gelsolin. This activity was evaluated by increasing the critical concentration for actin polymerization when gelsolin was added. (A) Results obtained in the presence of $0.2 \mathrm{mM} \mathrm{CaCl}_{2}$. (B) Results obtained in the presence of $2 \mathrm{mM}$ EGTA. To obtain each critical concentration, the amount of polymerized actin at five different actin concentrations $(3,6,12,24$, or $36 \mu \mathrm{M})$ in the presence of unphosphorylated (closed circles) or phosphorylated (open circles) gelsolin, or in the absence of gelsolin (crosses), were determined by flow birefringence. These results were averages of three different sets of experiments. When no actin was present or polymerized, the flow birefringence is 4.3 . The calculated critical concentrations $(\mathrm{Cc})$ are shown in the insets. None, gelsolin was absent; $-\mathrm{P}$ and $+\mathrm{P}$, unphosphorylated and phosphorylated gelsolin were added, respectively. In this case, to obtain clearer results, all gelsolin samples used were DEAEpurified phosphorylated or unphosphorylated calf serum gelsolin (see $\mathrm{Ma}$ terials and Methods). 
phosphorylated gelsolin was used in the absence of $\mathrm{Ca}^{2+}$ was consistent with the fact that about $90 \%$ of the gelsolin in that sample was phosphorylated (see Material and Methods).

\section{Actin-nucleation activity of phosphorylated gelsolin}

Gelsolin has yet another activity in addition to the above two activities. This third activity also stimulates actin nucleation in $\mathrm{C} \mathrm{Ca}^{2+}$-dependent manner. When $\mathrm{Ca}^{2+}$ was present, gelsolin shortened the lag phase which was seen in the early stages of actin polymerization (Fig. 5A). When $\mathrm{Ca}^{2+}$ was absent, unphosphorylated gelsolin had no effect on actin nucleation, and only phosphorylated gelsolin stimulated actin nucleation and assembly (Fig. 5B). It is noted here that the amount of assembled actin at equilibrium using phosphorylated gelsolin in the absence of $\mathrm{Ca}^{2+}$ was consistent with the fact that about one third of the gelsolin in that sample was
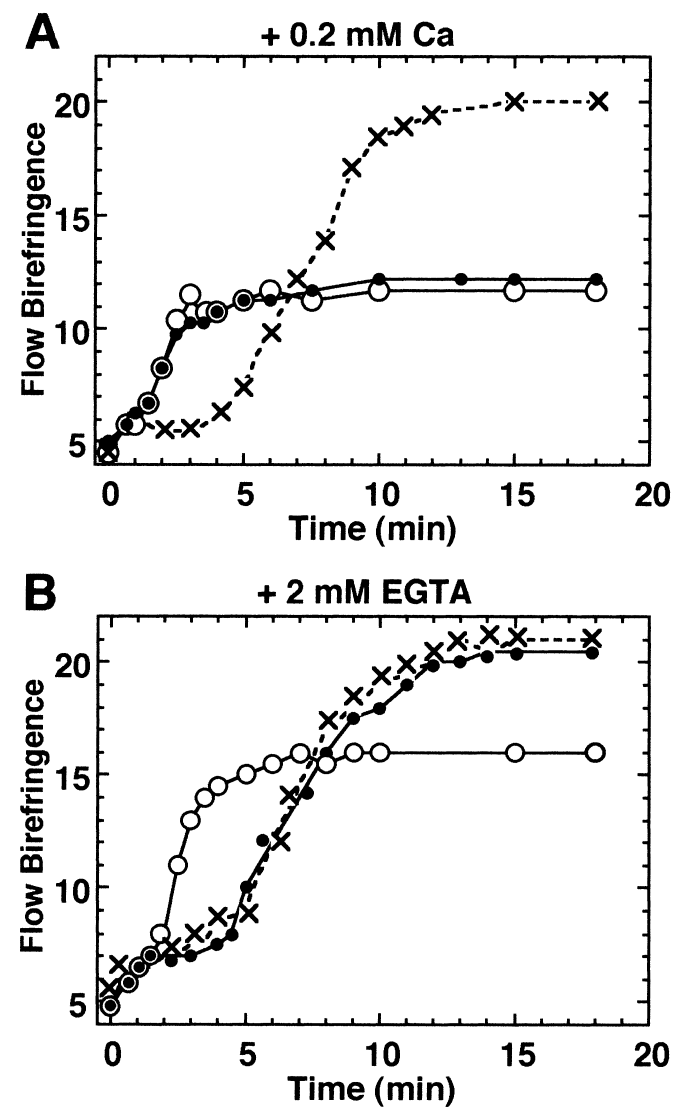

Fig. 5. The actin nucleating activity of phosphorylated and unphosphorylated plasma (calf serum) gelsolin. (A) The time course of actin polymerization in the presence of $0.2 \mathrm{mM} \mathrm{CaCl}_{2}$. (B) The time course of actin polymerization in the absence of $\mathrm{Ca}^{2+}(2 \mathrm{mM}$ EGTA). The closed and open circles show the amount of F-actin polymerized in the presence of unphosphorylated and phosphorylated gelsolin, respectively. The crosses show the amount of F-actin polymerized when no gelsolin was added. Note here that similar results were obtained when porcine serum gelsolin was phosphorylated instead of gelsolin from calf serum. phosphorylated.

\section{Discussion}

Since the plasma and cytoplasmic forms of gelsolin are encoded by a single gene and differ as the result of alternative splicing, both forms of gelsolin contain the same highly conserved core structure and differ only at the extended leader sequence of the plasma form (Bryan and Hwo, 1986; Kwiatkowski et al., 1985, 1986. Stella et al., 1994; Way and Weeds, 1998). This additional $\mathrm{NH}_{2}$-terminus region consists of at least 9 additional amino acid residues and occasionally contains signal and propeptide sequences. The consensus phosphorylation sequence of cdc2 kinase (Ser/Thr-Pro) is found in this region of porcine plasma gelsolin (Way and Weeds, 1988; Weeds et al., 1986; Yamakita et al., 1994; Yamashiro et al., 1990). This leader sequence region of plasma gelsolin is much less conserved and the amino acid sequence of calf serum gelsolin has not yet been solved. However, identical results were obtained in this study when calf plasma or porcine plasma gelsolin was phosphorylated. Additionally, it has recently been reported that cdc 2 kinase can phosphorylate several sites besides the well-known consensus phosphorylation sequence of Ser/Thr-Pro (Yamakita et al., 1994). Therefore, our results that only porcine plasma gelsolin but not porcine cytoplasmic gelsolin could be phosphorylated, indicate that the phosphorylation site is probably located within the extended leader sequence which exists only at the $\mathrm{NH}_{2}$-terminus of the plasma form of gelsolin. This was confirmed by the result that the CT17N fragments of calf and porcine plasma gelsolins were phosphorylated. Moreover, since the maximum efficiency of gelsolin phosphorylation did not exceed one mole/mole gelsolin, only a single site might be phosphorylated.

The activities of phosphorylated samples of gelsolin in the absence of $\mathrm{Ca}^{2+}$ were consistent with the percentage of phosphorylated protein in the total gelsolin sample (Figs. 25 ). These results suggest that the activities of phosphorylated gelsolin in the absence of calcium, and of unphosphorylated gelsolin in the presence of calcium, are essentially the same. Gelsolin has a $40 \mathrm{kDa} \mathrm{NH} \mathrm{NH}_{2}$-terminal half and a 45 $\mathrm{kDa} \mathrm{COOH}$-terminal half. Severing and subsequent capping, and nucleation activities are located in the $\mathrm{NH}_{2}$-terminal domain (Bryan and Hwo, 1986; Kwiatkowski et al., 1985, 1989; Yin et al., 1988), while $\mathrm{Ca}^{2+}$-binding sites are located in the COOH-terminal domain (Bryan and Hwo, 1986; Pope et al., 1995; Way et al., 1989; Weeds et al., 1995). It has been demonstrated that the $\mathrm{NH}_{2}$-terminal fragment shows the same activities as intact gelsolin but in a $\mathrm{Ca}^{2+}$-independent manner (Bryan and Hwo, 1986; Chaponnier et al., 1986; Yin et al., 1988). The $\mathrm{NH}_{2}$-terminal domain is thought to be involved in side-binding to F-actin, and probably penetrates into a filament to break a bond between two actin monomers, while continuously capping its barbed end. The $\mathrm{COOH}$-terminal half of gelsolin inhibits 
these interactions between actin and the $\mathrm{NH}_{2}$-terminal of gelsolin by masking the actin-binding sites of the $\mathrm{NH}_{2}$-terminal domain (Kwiatkowski et al., 1989). When micromolar concentrations of $\mathrm{Ca}^{2+}$ are added, a large conformational change, which permits the $\mathrm{NH}_{2}$-terminal half of gelsolin to interact with $\mathrm{F}$-actin by removing the masking, is induced in the $\mathrm{COOH}$-terminal half by the binding of $\mathrm{Ca}^{2+}$ to this region (Fig. 6) (Bryan and How, 1986; Chaponnier et al., 1986; Feinberg et al., 1998; Hellweg et al., 1993; Weber et $a l .$, 1991). Phosphorylated and unphosphorylated gelsolin, however, showed the same CD spectra in either the presence or absence of $\mathrm{Ca}^{2+}$ (data not shown). These results suggest either that the phosphorylation at the $\mathrm{NH}_{2}$-terminus of plasma gelsolin affects the $\mathrm{Ca}^{2+}$-dependence of this protein not by changing the structure of the $\mathrm{COOH}$-terminal half, or that the conformational change induced may be restricted to a small part of the $\mathrm{COOH}$-terminal region and/or is too small to be detected by CD spectra. For this reason, the affinity of phosphorylated gelsolin for F-actin might not be distinguishable from that of unphosphorylated gelsolin, even when $\mathrm{Ca}^{2+}$ is absent (data not shown).

The three-dimensional structure of gelsolin has been speculated to be "claw-like" in that its $\mathrm{NH}_{2}$ - and $\mathrm{COOH}$-termini are positioned near each other (Fig. 6); this speculation was recently confirmed by crystallography (Burtnick et al., 1997). This closed claw-like structure can be opened by $\mathrm{Ca}^{2+}$-binding as described above and this opening may expose the gelsolin active sites to actin. Moreover, it has been reported that there is a pseudo-actin sequence with several

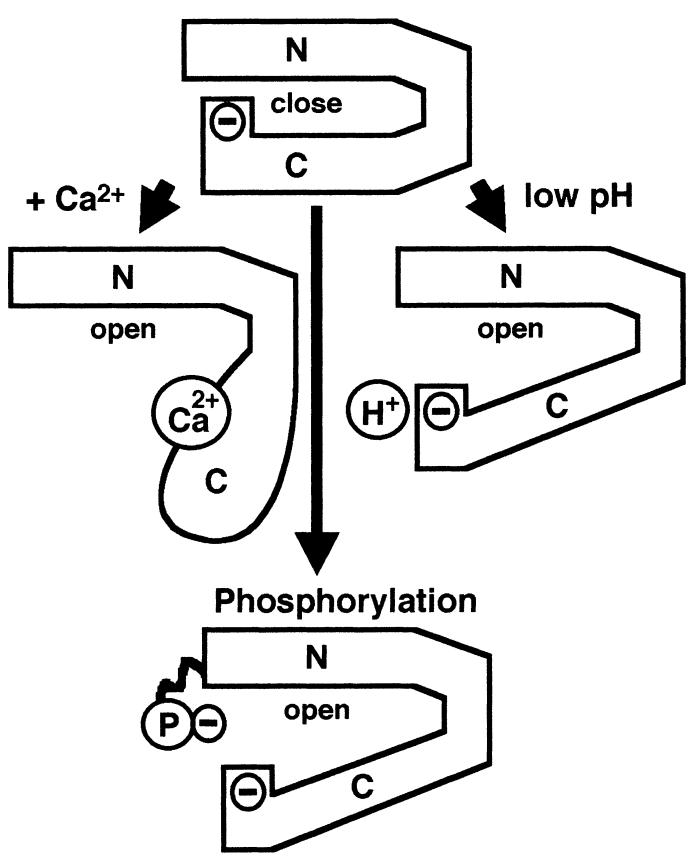

Fig. 6. A schematic model shows the conformational change of plasma gelsolin induced by the addition of $\mathrm{Ca}^{2+}$, by decreasing the $\mathrm{pH}$, or by phosphorylation. acidic amino residues similar to that found on the $\mathrm{NH}_{2}$-terminus of actin, near the carboxyl-end of the gelsolin $\mathrm{COOH}$-terminal, and that sequence seems to be important for the $\mathrm{Ca}^{2+}$-regulation of gelsolin (Kwiatkowski et al., 1989). When the $\mathrm{NH}_{2}$-terminus of gelsolin is phosphorylated, gelsolin shows its various activities even when $\mathrm{Ca}^{2+}$ is absent, and this may result from opening of the claw-like structure of gelsolin by electrical repulsive forces between both peptide ends of this protein (Fig. 6). Similarly, when the $\mathrm{pH}$ is lower than 6.0, gelsolin becomes active even when $\mathrm{Ca}^{2+}$ is absent (Lamb et al., 1993), probably since the negative charges of the $\mathrm{COOH}$-terminus pseudo-actin domain would be cancelled (Fig. 6) (Chaponnier et al., 1986, Kwiatkowski et al., 1989). It has recently been reported that human gelsolin could be phosphorylated by c-Src kinase at the Tyr438 residue located in the S4 segment, and the property of this phosphorylation has been revealed (De Corte et al., 1997, 1999). This phosphorylation is stimulated by phosphatidylinositol 4,5-bisphosphate (PIP2), a negative regulator of gelsolin activities (De Corte et al., 1997). It is thought that phosphorylation at this tyrosine residue and actin-binding of gelsolin hinder each other sterically, because tyrosine

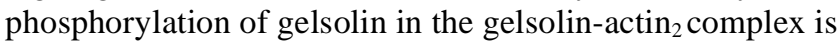
almost completely inhibited (De Corte et al., 1999). This opposing effect of tyrosine phosphorylation may be due to the location of its phosphorylation site. The S4 segment that contains the tyrosine phosphorylation site is located near the root of the claw-like structure of gelsolin, while the site of phosphorylation found in our study is located at the tip of the claw-like structure.

These findings may help us understand the mechanism of $\mathrm{Ca}^{2+}$-regulation of this well-known actin-binding protein found widely in cells and tissues, and also may help us understand general mechanisms of how protein phosphorylation can modify protein function, and may even provide a novel possible approach for the modification of enzyme activities. To investigate more detailed structural and mechanistic information concerning how proteins work, or to construct useful new proteins, several approaches have been developed by protein engineering using the genetic and chemical modification of proteins (Douglas, 1992; Fersht and Winter, 1992; Neidleman, 1994; Shao and Arnold, 1996). Since the site of phosphorylation studied in this report appears to be a single one and since it is located within an extended sequence that only plasma gelsolins have at their $\mathrm{NH}_{2}$-terminus, a region which does not contribute to the activity of gelsolin, our results suggests that single charge modifications, such as phosphorylation, at sites away from a protein's core structure can alter a protein's function.

For the same reason, it is not likely that the phosphorylation studied in this report is actually functioning in living cells, since the kinase fraction used contains primarily cdc2 kinase activity. However, regulation of the activities of gelsolin using this artificial phosphorylation system is very simple and reversible (Fig. 2, B and C). On the other hand, 
the reported mechanisms of gelsolin regulation that depend on calcium and PIP2 are very complicated and still remain unclear (DiNubile 1998; Janmey and Stossel, 1987, Lin et al., 1997; Yin, 1987). As described above, human gelsolin can also be phosphorylated by c-Src kinase, as reported recently (De Corte et al., 1997, 1999). Therefore, there is a possibility that still undiscovered kinases phosphorylate and regulate cytoplasmic gelsolin in living cells, and that cells have evolved mechanisms for regulating these proteins.

Acknowledgments. We thank Dr. Helen L. Yin for the kind gift of the antibody which recognizes the $\mathrm{COOH}$-terminal half region of gelsolin $(2 \mathrm{C} 4)$.

\section{References}

Arisaka, F., Noda, H., and Maruyama, K. 1975. Kinetic analysis of the polymerization process of actin. Biochim. Biophys. Acta., 400: 263274.

Bryan, J. and Hwo, S. 1986. Definition of an N-terminal actin-binding domain and a $\mathrm{C}$-terminal $\mathrm{Ca}^{2+}$ regulatory domain in human brevin. $J$. Cell Biol., 102: 1439-1446.

Bryan, J. 1988. Gelsolin has three actin-binding sites. J. Cell Biol., 106: 1553-1562.

Burtnick, L. D., Koepf, E. K., Grimes, J., Jones, E. Y., Stuart, D. I., McLaughlin, P. J., and Robinson, R. C. 1997. The crystal structure of plasma gelsolin: implications for actin severing, capping, and nucleation. Cell, 90: 661-670.

Chaponnier, C., Janmey, P. A., and Yin, H. L. 1986. The actin filament-severing domain of plasma gelsolin. J. Cell Biol., 103: 1473-1481.

Cunningham, C. C., Stossel, T. P., and Kwiatkowski, D. J. 1991. Enhanced mobility in NIH 3T3 fibroblasts that overexpress gelsoln. Science, 251: $1233-1236$.

De Corte, V., Gettemans, J., and Vandekerckhove, J. 1997. Phosphatidylinositol 4,5-bisphosphate specifically stimulates PP60 (c-src) catalyzed phosphorylation of gelsolin and related actin-binding proteins. FEBS Lett., 401: 191-196.

De Corte, V., Demol, H., Goethals, M., Van Damme, J., Gettemans, J., and Vandekerckhove, J. 1999. Identification of Tyr438 as the major in vitro c-Src phosphorylation site in human gelsolin: a mass spectrometric approach. Protein Sci., 8: 234-241.

DiNubile, M., J. 1998. Nucleation and elongation of actin filaments in the presence of high speed supernate from neutrophil lysates: modulating effects of $\mathrm{Ca}^{2+}$ and phosphatidylinositol-4,5-bisphosphate. Biochim. Biophys. Acta., 1405: 85-98.

Douglas, K. T. 1992. Alteration of enzyme specificity and catalysis. Curr. Opin. Biotechnol., 3: 370-377.

Feinberg, J., Kwiatek, O., Astier, C., Diennet, S., Mery, J., Heitz, F., Benyamin, Y., and Roustan, C. 1998. Capping and dynamic relation between domains 1 and 2 of gelsolin. J. Pept. Sci., 4: 116-127.

Fersht, A. and Winter, G. 1992. Protein engineering. Trends. Biochem. Sci., 17: 292-295.

Haddad, J. G., Harper, K. D., Guoth, M., Pietra, G. G., and Sanger, S. W. 1990. Angiopathic consequences of saturating the plasma scavenger system for actin. Proc. Natl. Acad. Sci. USA, 87: 1381-1385.

Hellweg, T., Hinssen, H., and Eimer, W. 1993. The $\mathrm{Ca}^{2+}$-induced conformational change of gelsolin is located in the carboxyl-terminal half of the molecule. Biophys. J., 65: 799-805.

Ishikawa, R., Yamashiro, S., and Matsumura, F. 1989. Annealing of gelsolin-severed actin fragments by tropomyosin in the presence of $\mathrm{Ca}^{2+}$. Potentiation of the annealing process by caldesmon. J. Biol. Chem., 264: $16764-16770$.
Janmey, P. A. and Stossel, T. P. 1987. Modulation of gelsolin function by phosphatidylinositol 4,5-bisphosphate. Nature, 325: 362-364.

Kilhoffer, M. C. and Gerard, D. 1985. Fluorescence study of brevin, the $\mathrm{Mr} 92000$ actin-capping and -fragmenting protein isolated from serum. Effect of $\mathrm{Ca}^{2+}$ on protein conformation. Biochemistry, 24: 5653-5660.

Kwiatkowski, D. J., Janmey, P. A., Mole, J. E., and Yin, H. L. 1985. Isolation and properties of two actin-binding domains in gelsolin. J. Biol. Chem., 260: 15232-15238.

Kwiatkowski, D. P., Stossel, T. P., Orkin, S. H., Mole, J. E., Colten, H. R., and Yin, H. L. 1986. Plasma and cytoplasmic gelsolins are encoded by a single gene and contain a duplicated actin-binding domain. Nature, 323: 455-458.

Kwiatkowski, D. J., Mehl, R. M., and Yin, H. L. 1988. Genomic organization and biosynthesis of secreted and cytoplasmic forms of gelsolin. J. Cell Biol., 106: 375-384.

Kwiatkowski, D. J., Janmey, P. A., and Yin, H. L. 1989. Identification of critical functional and regulatory domains in gelsolin. J. Cell Biol., 108: $1717-1726$.

Lamb, J. A., Allen, P. G., Tuan, B. Y., and Janmey, P. A. 1993. Modulation of gelsolin function. Activation at low $\mathrm{pH}$ overrides $\mathrm{Ca}^{2+}$ requirement. J. Biol. Chem., 268: 8999-9004.

Lin, K., Wenegieme, E. F., Lu, P., Chen, C., and Yin, H. L. 1997. Gelsolin binding to phosphatidylinositol 4,5-bisphosphate is modulated by calcium and pH. J. Biol. Chem., 272: 20443-0450.

Neidleman, S. L. 1994. New applications of biocatalysts. Curr. Opin. Biotechnol., 5: 206-211.

Pope, B., Maciver, S., and Weeds, A. 1995. Localization of the calciumsensitive actin monomer binding site in gelsolin to segment 4 and identification of calcium binding sites. Biochemistry, 34: 1583-1588.

Rouayrenc, J. F., Fattoum, A., Gabrion, J., Audemard, E., and Kassab, R. 1984. Muscle gelsolin: isolation from heart tissue and characterization as an integral myofibrillar protein. FEBS Lett., 167: 52-58.

Rouayrenc, J. F., Fattoum, A., Mejean, C., and Kassab, R. 1986. Characterization of the $\mathrm{Ca}^{2+}$-induced conformational changes in gelsolin and identification of interaction regions between actin and gelsolin. Biochemistry 25: 3859-3867.

Shao, Z. and Arnold, F. H. 1996. Engineering new functions and altering existing functions. Curr. Opin. Struct. Biol., 6: 513-518.

Stella, M. C., Schauerte, H., Straub, K. L., and Leptin, M. 1994. Identification of secreted and cytosolic gelsolin in Drosophila. J. Cell Biol., 125: 607-616.

Takiguchi, K. 1991. Heavy meromyosin induces sliding movements between antiparallel actin filaments. J. Biochem., 109: 520-527.

Vasconcellos, C. A. and Lind, S. E. 1993. Coordinated inhibition of actin induced platelet aggregation by plasma gelsolin and vitamin D-binding protein. Blood, 82: 3648-3657.

Way, M. and Weeds, A. 1988. Nucleotide sequence of pig plasma gelsolin. Comparison of protein sequence with human gelsolin and other actin-severing proteins shows strong homologies and evidence for large internal repeats. J. Mol. Biol., 203: 1127-1133.

Way, M., Gooch, J., Pope, B., and Weeds, A. G. 1989. Expression of human plasma gelsolin in Escherichia coli and dissection of actin binding sites by segmental deletion mutagenesis. J. Cell Biol., 109: 593-605.

Weber, A., Pring, M., Lin, S. L., and Bryan, J. 1991. Role of the N- and Cterminal actin-binding domains of gelsolin in barbed filament end capping. Biochemistry, 30: 9327-9334.

Weeds, A. G., Gooch, J., Pope, B., and Harris, H. E. 1986. Preparation and characterization of pig plasma and platelet gelsolins. Eur. J. Biochem., 161: 69-76.

Weeds, A. G., Gooch, J., McLaughlin, P., Pope, B., Bengtsdotter, M., and Karlsson, R. 1995. Identification of the trapped calcium in the gelsolin segment 1-actin complex: implications for the role of calcium in 
the control of gelsolin activity. FEBS Lett., 360: 227-230.

Witke, W., Sharpe, A. H., Hartwig, J. H., Azuma, T., Stossel, T. P., and Kwiatkowski, D. J. 1995. Hemostatic, inflammatory, and fibroblast responses are blunted in mice lacking gelsolin. Cell, 81: 41-51.

Yamakita, Y., Yamashiro, S., and Matsumura, F. 1994. In vivo phosphorylation of regulatory light chain of myosin II during mitosis of cultured cells. J. Cell Biol., 124: 129-137.

Yamashiro-Matsumura, S. and Matsumura, F. 1985. Purification and characterization of an F-actin-bundling 55-kilodalton protein from HeLa cells. J. Biol. Chem., 260: 5087-5097.

Yamashiro, S., Yamakita, Y., Ishikawa, R., and Matsumura, F. 1990. Mitosis-specific phosphorylation causes $83 \mathrm{~K}$ non-muscle caldesmon to dissociate from microfilaments. Nature, 344: 675-678.

Yamashiro, S., Yamakita, Y., Hosoya, H., and Matsumura, F. 1991. Phosphorylation of non-muscle caldesmon by p34cdc2 kinase during mitosis. Nature, 349: 169-172.
Yin, H. L. and Stossel, T. P. 1979. Control of cytoplasmic actin gel-sol transformation by gelsolin, a calcium-dependent regulatory protein. Nature, 281: 581-586.

Yin, H. L., Kwiatkowski, D. J., Mole, J. E., and Cole, F. S. 1984. Structure and biosynthesis of cytoplasmic and secreted variants of gelsolin. $J$. Biol. Chem., 259: 5271-5276.

Yin, H. L. 1987. Gelsolin: calcium- and polyphosphoinositide-regulated actin-modulating protein. Bioessays, 7: 176-179.

Yin, H. L., Iida, K., and Janmey, P. A. 1988. Identification of a polyphosphoinositide-modulated domain in gelsolin which binds to the sides of actin filaments. J. Cell Biol., 106: 805-812.

(Received for publication, December 14, 1999

and in revised form, January 21, 2000) 